\title{
Exhaled nitric oxide collected with two different mouthpieces: a study in asthmatic patients
}

A.S. Leme ${ }^{1}$, D.I. Kasahara ${ }^{1}$, M.P.T. Nunes ${ }^{1}$, M.A. Martins ${ }^{1}$ and J.E. Vieira1,2
${ }^{1}$ Disciplina de Clínica Geral, Laboratório de Terapêutica Experimental 1 (LIM 20) and 2Disciplina de Anestesiologia, Faculdade de Medicina, Universidade de São Paulo, São Paulo, SP, Brasil

\section{Correspondence \\ J.E. Vieira \\ Laboratório de Terapêutica \\ Experimental I, LIM 20 \\ Faculdade de Medicina, USP \\ Av. Dr. Arnaldo, 455, Sala 1216 \\ 01246-903 São Paulo, SP \\ Brasil \\ Fax: + 55-11-3085-0992 \\ E-mail: joaquimev@ hotmail.com \\ Presented in part at the 97 th International Conference of the American Thoracic Society, San Francisco, CA, USA, May 18-23, 2001.}

Research supported by CNPq, FAPESP and PRO NEX-MCT.

Received 0 ctober 17, 2001

Accepted June 20, 2002

\section{Abstract}

Techniques for collecting exhaled nitric oxide (ENO) recommend the use of antibacterial filters of $0.3 \mu \mathrm{m}$. The aim of the present study was to compare the measurements of ENO obtained with two different filtering devices. Air samples from 17 asthmatic and 17 non-asthmatic subjects were collected by a recommended off-line technique using two different mouthpieces: 1) the Sievers disposable tool (A) under a breathing pressure of $18 \mathrm{cmH}_{2} \mathrm{O}$, and 2) a mouthpiece containing a HEPA filter (B) under a breathing pressure of $12 \mathrm{cmH}_{2} \mathrm{O}$. The nitric oxide samples were collected into an impermeable reservoir bag. Values for ENO were compared using two-way repeated measures ANOVA followed by the Tukey test. Agreement was assessed by Bland-Altman analysis. ENO values obtained with mouthpieces A and $B$ were comparable for asthmatic (mean \pm SEM, $42.9 \pm 6.9$ vs 43.3 $\pm 6.6 \mathrm{ppb})$ and non-asthmatic (13.3 \pm 1.3 vs $13.7 \pm 1.1 \mathrm{ppb})$ subjects. There was a significant difference in ENO between asthmatics and non-asthmatics using either mouthpiece $\mathrm{A}(\mathrm{P}<0.001)$ or $\mathrm{B}(\mathrm{P}<0.001)$. There was a positive correlation between mouthpiece A and mouthpiece B for both groups. The Bland-Altman limits of agreement were considered to be acceptable. Mouthpiece B was less expensive than A, and these data show that it can be used without compromising the result. Our data confirm reports of higher ENO values in the presence of airway inflammation.

\section{Introduction}

Nitric oxide (NO), a highly reactive gas involved in several pathophysiologic processes, is synthesized by endothelia and neuronal tissue cells and by macrophages. NO may participate in arterial pressure regulation, neuronal communication and immune system defense. High NO production may be associated with diseases such as sepsis, stroke and cerebrovascular disease, neuronal de-

\section{Key words}

- Exhaled nitric oxide

- Asthma

- Nitric oxide collecting

- Filter apparatus generation, diabetes, arthritis and several chronic inflammatory conditions $(1,2)$.

Asthma is a worldwide disease. Symptoms include dyspnea, cough and difficult respiration associated or not with wheezing that have been related to the release of inflammatory airway mediators (3). The treatment and control of asthma have been recommended by guidelines such as the Expert Panel Report 2 (National Heart, Lung, and Blood Institute, NIH, 1997) (4). During the 
last few years, emphasis has changed from bronchospasm control, surely necessary, to the control of airway inflammation.

NO participates in the physiologic regulation of bronchomotor tonus, in diseases such as asthma $(5,6)$. Exhaled NO (ENO) is elevated in asthmatic persons compared to non-asthmatic individuals $(7,8)$ and is derived mainly from peripheral airways $(9,10)$. The higher ENO values for asthmatic persons have been related to airway inflammation mainly when eosinophils are present (11). ENO is also elevated during a late allergenic response (12) although they are reduced during inhaled corticoid treatment (13).

Recently the techniques used to collect and to measure ENO have been standardized (14). Included in the recommendations is the use of antibacterial filters with a filtering capacity of $0.3 \mu \mathrm{m}$. A disposable filtering material is available from Sievers (Sievers Instruments Inc., Boulder, CO, USA). A second device has been constructed to use the high efficiency particulate air (HEPA) filters with similar filtering capacity to the Sievers filters.

The objective of the present investigation was to compare ENO measurements obtained from non-asthmatic healthy volunteers and asthmatic subjects using two filtering mouthpieces.

\section{Material and Methods}

The protocol was approved by the Ethics Committee of the University Hospital and

Figure 1. A photograph of the mouthpiece containing the HEPA filter assembled and separated into three parts showing the screw portion where the two connect. The HEPA pad is located inside the device.

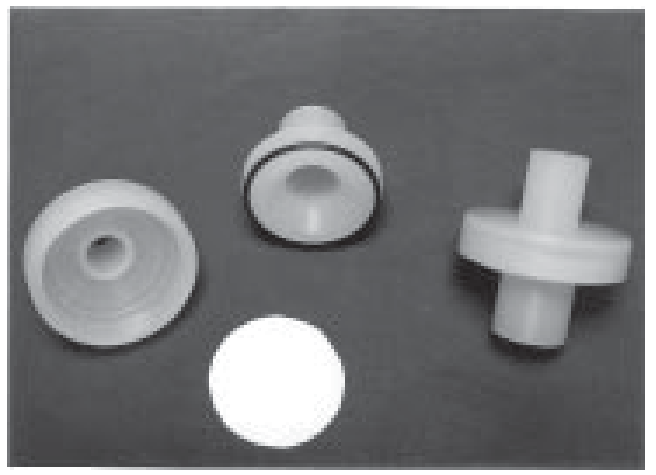

informed consent was obtained from the subjects.

Seventeen asthmatic and 17 healthy nonasthmatic volunteers were invited to participate in the study by providing exhaled air samples in order to compare ENO collected by the recommended off-line technique using two different devices (Figure 1): 1) the Sievers mouthpiece with a built-in $0.3-\mu \mathrm{m}$ bacterial filter (A), and 2) a mouthpiece containing a $0.3-\mu \mathrm{m}$ bacterial HEPA filter (Trox Technik, Curitiba, PR, Brazil) (B). Subjects were required to inhale orally up to their total lung capacity first through mouthpiece A and then through mouthpiece B, both attached to a Sievers sampling kit. This kit contains a pressure gauge and an inspiratory filter that reduces the $\mathrm{NO}$ level from the inhaled air to a very low concentration.

Once the subject had inhaled to total lung capacity, a gentle exhalation maneuver into the Mylar bag (Sievers) was performed through the sampling kit without any breathholding (mean oral NO). The volunteer using the A mouthpiece was instructed to achieve a breathing pressure of $18 \mathrm{cmH}_{2} \mathrm{O}$ monitored by the pressure gauge, which gave a flow rate of $250 \mathrm{ml} / \mathrm{s}$. During this expiratory time, he was instructed to push in a stainless steel valve of the sampling kit after $3 \mathrm{~s}$ of exhalation and to continue for about $2 \mathrm{~s}$, producing a collected volume larger than $50 \mathrm{ml}$ (duplicate samples). This procedure was repeated using the $\mathrm{B}$ mouthpiece with the volunteer reaching a breathing pressure of $12 \mathrm{cmH}_{2} \mathrm{O}$, which gave a flow rate of 200 $\mathrm{ml} / \mathrm{s}$. The breathing sample was collected into an NO-impermeable reservoir bag (Mylar bag) with a volume capacity of 1.5 liters. The bags were sealed and subsequently analyzed for ENO by chemiluminescence (Sievers, model NOA 280).

The resistance of the Sievers sampling kit with the A or B mouthpiece was determined using an Inter 5 ventilator (Intermed, São Paulo, SP, Brazil) with the application of a quadratic constant flow. 


\section{Statistical analysis}

Statistical analysis was performed using the SigmaStat 2.0 software (SigmaStat for Windows version 2.03, SPSS Inc.). All data are reported as means \pm SEM. ENO values were compared by two-way repeated measures analysis of variance for one factor of repetition followed by the Tukey test for multiple comparisons, with the level of significance set at a $\mathrm{P}<0.05$. The Pearson correlation coefficient was used in order to compare the devices. Agreement of the results obtained with the two mouthpieces was determined by the Bland-Altman method calculated as the mean difference and the standard deviation of the differences between $\mathrm{A}$ and $\mathrm{B}$ NO values. This mean added or subtracted to doubled standard deviation gives the "limits of agreement" (15).

\section{Results}

The measurements of ENO using mouthpieces A and B for asthmatic patients (42.9 \pm $6.9 v s 43.3 \pm 6.6 \mathrm{ppb})$ or for non-asthmatic subjects $(13.3 \pm 1.3$ vs $13.7 \pm 1.1 \mathrm{ppb})$ were the same (Figure 2). ENO from asthmatics was higher than ENO from non-asthmatics using either device A $(42.9 \pm 6.9$ vs $13.3 \pm$ $1.3 \mathrm{ppb}, \mathrm{P}<0.001)$ or device $\mathrm{B}(43.3 \pm 6.6 v \mathrm{~s}$ $13.7 \pm 1.1 \mathrm{ppb}, \mathrm{P}<0.001)$.

There was a strong positive correlation between the results obtained with filters A and $\mathrm{B}$ for both groups (Figure 3).

The Bland-Altman diagrams plot the difference in the exhaled nitric oxide measured between techniques (Figure 4). The agreement between techniques is demonstrated by a plot of differences against mean values of exhaled nitric oxide. In this plot the solid bar represents the mean difference and broken lines indicate $\pm 2 \mathrm{SD}$ from the mean. The figure shows the various measures to be reproduced because the individual points on the Bland-Altman plot are randomly scattered around the overall average difference and most points fall within $2 \mathrm{SD}$ of the overall difference. A random scatter with several points outside the 2 SD would indicate a weak agreement.
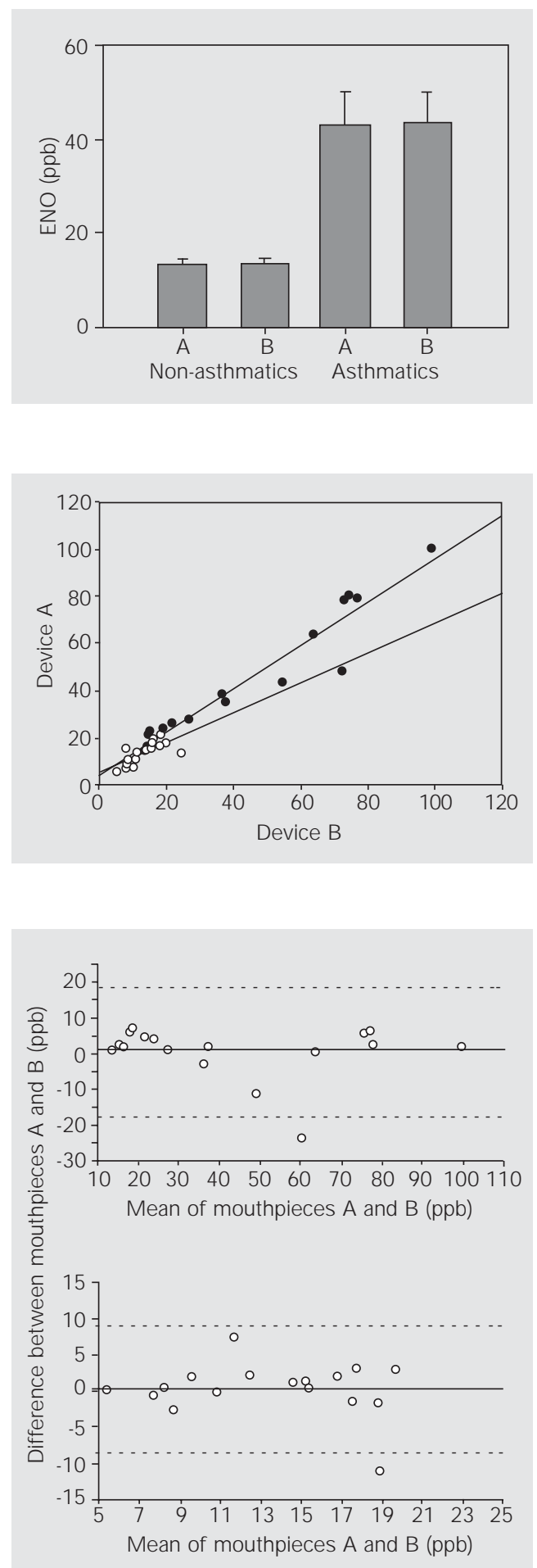

Figure 2. Exhaled nitric oxide (ENO) obtained with the different devices for asthmatic ( $\mathrm{N}=$ 17) and non-asthmatic subjects ( $\mathrm{N}=17)$. There was no difference in ENO between mouthpieces $A$ and $B$ for asthmatic patients or non-asthmatic subjects. However, there was a difference in ENO when asthmatic patients were compared with non-asthmatics using either device $A$ $(P<0.001)$ or device $B(P<0.001)$.

Figure 3. Correlation curve of exhaled nitric oxide (ppb) obtained from non-asthmatic (open circles) $(r=0.508)$ and asthmatic subjects (filled circles) $(r=0.930)$. There was a positive correlation between the different devices for both non-asthmatic and asthmatic subject data.

Figure 4. Bland-Altman diagram comparing exhaled nitric oxide (ENO) measured with the Sievers mouthpiece (A) and the mouthpiece containing a HEPA filter (B) in asthmatic patients (top) and non-asthmatic subjects (bottom). The mean difference was $0.49 \mathrm{ppb}$ and the limits of agreement were 18.74 and -17.75 for ENO from asthmatic patients. These limits are acceptable and pertain to the 2 SD range of B-A analyses. 
Mouthpiece resistance was checked by applying quadratic constant flow. Mouthpiece A under a constant flow of $16 \mathrm{l} / \mathrm{min}$ $(260 \mathrm{ml} / \mathrm{s})$ produced a sampling kit pressure of $18 \mathrm{cmH}_{2} \mathrm{O}$ and in the Inter 5 ventilator a system pressure of $21 \mathrm{cmH}_{2} \mathrm{O}$. Mouthpiece $\mathrm{B}$ under a constant flow of $12 \mathrm{l} / \mathrm{min}(200$ $\mathrm{ml} / \mathrm{s}$ ) produced an equal Inter 5 ventilator pressure of $21 \mathrm{cmH}_{2} \mathrm{O}$ and a pressure of 12 $\mathrm{cmH}_{2} \mathrm{O}$ in the sampling kit.

\section{Discussion}

The two mouthpieces, i.e., the Sievers device and the device containing a HEPA filter, were the same in their capacity to correctly collect ENO in higher or lower concentrations from asthmatic patients or healthy volunteers, respectively.

The main rationale behind our study was to compare the efficacy of the Sievers mouthpiece with a prototype manufactured in Brazil which costs approximately six times less than the imported mouthpiece. A significant part of the savings is that the mouthpiece of the HEPA filter apparatus is reusable.

The use of standardized ENO collecting methods has been recommended in order to avoid bias in the measurement (14). We have replaced the standardized piece that holds a built-in filter with a new one without changing the characteristics of the measurements. The pressure inside the sampling kit that provides the breathing flow to be redirected to the Mylar collection bag is different (12 $\mathrm{cmH}_{2} \mathrm{O} v s 18 \mathrm{cmH}_{2} \mathrm{O}$ ). However, this difference did not change the final amount of ENO measured. We tested its filtering performance in two situations: with asthmatic subjects, who might exhale higher levels of $\mathrm{NO}$, and with healthy volunteers, from whom a lower ENO concentration is expected. Asthmatics may also not feel comfortable blowing into an apparatus with high airflow resistance, a situation probably well tolerated by nonasthmatics.
The pressure inside the mouth did not exceed $21 \mathrm{cmH}_{2} \mathrm{O}$ for the two mouthpieces, as measured by tests performed in our laboratory using an Inter 5 ventilator. This limitation probably reflects the respiratory system charge imposed by these maneuvers. Although no other lower or higher pressure was tested, this pressure seems to be a good standard to reach $21 \mathrm{cmH}_{2} \mathrm{O}$ in the mouth during the expiratory maneuver. None of the patients or volunteers complained about such effort.

The modified HEPA filter used instead of the original Sievers mouthpiece has a filtering capacity of less than $0.3 \mu \mathrm{m}$. This capacity was tested with heated dioctyl phthalate which creates a smoke averaging $0.3 \mu \mathrm{m}$. According to the Lydall Group technical support (www.lydall.com), this smoke is used to challenge the filter media at a flow rate of $5.33 \mathrm{~cm}$ per second with the penetration recorded. The HEPA filter media has a maximum efficiency of $99.97 \%$, meaning that only $0.03 \%$ of the smoke within $0.3 \mu \mathrm{m}$ penetrates the filter area. For this reason, our device can be considered to have the recommended antibacterial capacity (14).

The results showed a good Pearson correlation coefficient. However, even a good correlation may not reflect the agreement between the two results. In order to determine if the correlation coefficients would not be misleading with respect to the use of the new HEPA filter, the Bland-Altman method for clinical measurement comparison of any new technique with an established one was applied to the results obtained with these two mouthpieces (15). The agreement among the NO data obtained by devices $\mathrm{A}$ and $\mathrm{B}$ was confirmed by BlandAltman analysis (15). This method estimates the average bias of one method relative to the other and also how the methods are likely to agree for an individual. Figure 4 shows that each of the limits of agreement is small enough to qualify both tools containing different filters as reliable to measure ENO in 
both subject groups. For asthmatics the limits are wider than for non-asthmatics, probably because of the heterogeneity of the asthmatic group. However, it must be noted that there are large confidence intervals in the measurements with both filters.

\section{Acknowledgments}

We are very grateful to Cristian Alexandre Sugmoto who designed the plastic component of the B device.

\section{References}

1. Nathan C \& Xie QW (1994). Regulation of biosynthesis of nitric oxide. J oumal of Biological Chemistry, 269: 13725-13728.

2. Moncada S, Palmer RM \& Higgs EA (1991). Nitric oxide: physiology, pathophysiology, and pharmacology. Pharmacological Reviews, 43: 109-142.

3. Sandford A, Weir T \& Pare P (1996). The genetics of asthma. American J ournal of Respiratory and Critical Care Medicine, 153: 1749-1765.

4. National Heart, Lung, and Blood Institute (1997). Expert Panel Report 2: Guidelines for the Diagnosis and Management of Asthma. National Institutes of Health, Bethesda, MD, USA.

5. Barnes PJ \& Belvisi MG (1993). Nitric oxide and lung disease. Thorax, 48: 10341043.

6. Gaston B, Drazen J M, Loscalzo J \& Stamler JS (1994). The biology of nitrogen oxides in the airways. American J ournal of Respiratory and Critical Care Medicine, 149 (Part 1): 538-551.

7. Alving $K$, Weitzberg $E \&$ Lundberg J M
(1993). Increased amount of nitric oxide in exhaled air of asthmatics. European Respiratory J ournal, 6: 1368-1370.

8. Persson MG, Zetterstrom O, Agrenius V, Ihre E \& Gustafsson LE (1994). Singlebreath nitric oxide measurements in asthmatic patients and smokers. Lancet, 343 : 146-147.

9. Kharitonov SA, Chung KF, Evans D, O'Connor BJ \& Barnes PJ (1996). Increased exhaled nitric oxide in asthma is mainly derived from the lower respiratory tract. American J ournal of Respiratory and Critical Care Medicine, 153 (Part 1): 17731780.

10. Massaro AF, Mehta S, Lilly CM, Kobzik L, Reilly JJ \& Drazen J M (1996). Elevated nitric oxide concentrations in isolated lower airway gas of asthmatic subjects. American J ournal of Respiratory and Critical Care Medicine, 153: 1510-1514.

11. J atakanon A, Lim S, Kharitonov SA, Chung KF \& Barnes PJ (1998). Correlation between exhaled nitric oxide, sputum eosinophils, and methacholine respon- siveness in patients with mild asthma. Thorax, 53: 91-95.

12. Kharitonov SA, O'Connor BJ , Evans DJ \& Barnes PJ (1995). Allergen-induced late asthmatic reactions are associated with elevation of exhaled nitric oxide. American J ournal of Respiratory and Critical Care Medicine, 151: 1894-1899.

13. Kharitonov SA, Yates D, Robbins RA, Logan-Sinclair R, Shinebourne EA \& Barnes PJ (1994). Increased nitric oxide in exhaled air of asthmatic patients. Lancet, 343: 133-135.

14. American Thoracic Society (1999). Recommendations for standardized procedures for the online and off-line measurement of exhaled lower respiratory nitric oxide and nasal nitric oxide in adults and children. American J ournal of Respiratory and Critical Care Medicine, 160: 21042117.

15. Bland J M \& Altman DG (1986). Statistical methods for assessing agreement between two methods of clinical measurement. Lancet, 1: 307-310. 